\title{
PERAN MODERASI UKURAN PERUSAHAAN TERHADAP FAKTOR-FAKTOR YANG MEMPENGARUHI ISLAMIC SOCIAL REPORTING
}

\author{
Desy Dwi Ayu Lestari, Mochlasin Mochlasin \\ Institut Agama Islam Negeri (IAIN) Salatiga, Indonesia \\ desydwiayu.asfebi@gmail.com,mochlasin@iainsalatiga.ac.id \\ https://doi.org/10.46367/jas.v5i2.387
}

Received: Aug 20, 2021 Revised: Nov 18, 2021 Accepted: Nov 25, 2021 Published: Dec 21, 2021

\begin{abstract}
Disclosure of Islamic Social Reporting (ISR) has a role in the company, and the broad ISR will lead the company to a positive impact. This study aims to analyze the effect of profitability, leverage, and institutional ownership on Islamic Social Reporting (ISR) disclosure with firm size as a moderating variable in companies listed on the Jakarta Islamic Index (JII) for the 2014-2019 period. Determination of the sample using the purposive sampling method. The data used are 84 company annual reports. The test analysis method uses Moderated Regression Analysis (MRA). The study results partially show that profitability, leverage, and institutional ownership do not affect ISR disclosure. Firm size can moderate the effect of leverage on ISR disclosure. Meanwhile, firm size cannot moderate the effect of profitability and institutional ownership on ISR disclosure. Companies with declining or increasing financial conditions cannot motivate companies to make more comprehensive disclosures. Companies with good intentions, of course, will continue to make broader disclosures in financial conditions up or down.
\end{abstract}

Keywords: Profitability, Leverage, Institutional Ownership, Islamic Social Reporting, Company Size.

\section{ABSTRAK}

Pengungkapan Islamic Social Reporting (ISR) memiliki peran dalam perusahaan, $I S R$ yang luas akan mengantarkan perusahaan pada dampak positif. Penelitian ini memiliki tujuan menganalisis pengaruh profitabilitas, leverage dan kepemilikan institusional terhadap pengungkapan Islamic Social Reporting (ISR) dengan ukuran perusahaan sebagai variabel moderasi pada perusahaan yang terdaftar di Jakarta Islamic Index (JII) periode 2014-2019. Penentuan sampel menggunakan metode purposive sampling. Data yang digunakan sebanyak 84 laporan tahunan perusahaan. Metode analisis uji menggunakan Moderated Regresion Analysis (MRA). Hasil penelitian secara parsial menunjukkan bahwa profitabilitas, leverage dan kepemilikan institusional tidak berpengaruh terhadap pengungkapan ISR. Ukuran perusahaan mampu memoderasi pengaruh leverage terhadap pengungkapan ISR. Sedangkan ukuran perusahaan tidak mampu memoderasi pengaruh profitabilitas dan kepemilikan institusional terhadap pengungkapan ISR. Perusahaan dengan kondisi keuangan yang menurun atau meningkat tidak dapat 
menjadi motivasi perusahaan melakukan pengungkapan lebih luas. Perusahaan dengan niat baik tentunya tetap akan melakukan pengungkapan lebih luas dalam kondisi keuangan naik atau turun.

Kata Kunci: Profitabilitas, Leverage, Kepemilikan Institusional, Islamic Social Reporting, Ukuran Perusahaan.

\section{PENDAHULUAN}

Keberadaan perusahaan mendatangkan dampak positif maupun negatif. Dampak positif terciptanya lapangan pekerjaan untuk warga yang berada di area perusahaan. Dampak negatif yang ditimbulkan berupa limbah yang berasal dari kegiatan operasi, jika limbah itu tidak diolah dengan baik maka dapat mengakibatkan pencemaran lingkungan di sekitar perusahaan. Adanya tanggung jawab sosial suatu kewajiban moral dan merupakan adaptasi serta kontribusi yang manjadi keharusan untuk dilakukan oleh perusahaan (Yunni 2019). Etika bisnis menjadi latar belakang perusahaan mengeluarkan kebijakan yang bermanfaat bagi lingkungannya. Corporate Social Responsibility (CSR) konsep etika bisnis bentuk kontribusi perseroan terhadap masyarakat dan strategi perusahaan berkaitan dengan lingkungan sekitarnya (Sitorus 2019). Berkembangnya ekonomi Islam dan pesatnya pertumbuhan pasar global halal serta menjadi trend dunia, sehingga memicu perkembangan Islamic Social Reporting (ISR).

Kinerja keuangan salah satu aspek finansial yang digunakan dalam penelitian ini yaitu rasio profitabilitas suatu entitas dalam bentuk return on asset (ROA). Profitabilitas menjadi perhatian lebih karena perusahaan harus berada pada posisi yang mengutungkan dalam menjalankan aktivitasnya. Saat profitabilitas tinggi perusahaan akan lebih luas melaksanakan pengungkapan ISR (Affandi and Nursita 2019). Aspek finansial selanjutnya yaitu leverage, dimana besarnya perusahaan yang dibiayai dengan utang dapat diketahui melalui leverage. Modal berasal dari kreditur dapat mendatangkan keuntungan yang lebih untuk perusahaan dengan kosekuensi perusahaan harus membayar bunga (Arif and Wawo 2016). Informasi yang luas dapat dipengaruhi dengan leverage tinggi, karena adanya dorongan atau tekanan. Perluasan infomasi sosial merupakan upaya agar para kreditor percaya perusahaan tidak melanggar covenants (perjanjian).

Kepemilikan institusional dapat mengontrol manajemen dengan proses pemantauan yang efektif, akan mempengaruhi tingkat pengungkapan yang bersifat wajib. Adanya kontrol manajemen yang tinggi akan meperlancar proses operasi perusahaan yang berdampak pada laba serta kepercayaan para kreditur (Nugraheni and Yuliani 2017). Kemudian ukuran perusahaan digunakan untuk mengevaluasi skala perusahaan. Perusahaan dengan skala besar, maka semakin banyak sumber dayanya, baik itu keuangan, sumber daya manusia atau fasilitas. Entitas besar lebih relatif stabil dan mampu menghasilkan laba lebih besar dibanding entitas kecil, juga tidak sulit masuk kedalam pasar modal, sehingga memperoleh penilaian lebih tinggi dari kreditur dan dapat mempengaruhi keuntungan perusahaan (Sari and Rani 2015).

Penelitian mengenai aspek profitabilitas yang diukur menggunakan $R O A$ dalam pengungkapan ISR sudah dilakukan oleh Taufik, Widianti, and Rafiqoh (2015); Rosiana, Arifin, and Hamdani (2015); Ramadhani, Desmiyawati, and 
Kurnia (2016); Setiawan, Asnawi, and Sofyani (2016); Hasanah, Widiyanti, and Sudarno (2018) dengan hasil yang beragam. Kemudian aspek leverage dalam pengungkapan ISR sudah pernah dikaji oleh Ramadhani, Desmiyawati, and Kurnia (2016); Pratama, Muchlis, and Wahyuni (2018); Hasanah, Widiyanti, and Sudarno (2018); Astuti and Nurkhin (2019) memiliki hasil yang beragam juga. Selanjutnya Penelitian mengenai aspek kepemilikan institusioal dalam pengungkapan ISR sudah pernah juga dilakukan oleh Nigrum, Fachrurrozie, and Jayanto (2013); Nugraheni and Yuliani (2017); Firdaus, Darlis, and Indrawati (2017); Pratama, Muchlis, and Wahyuni (2018) dengan hasil temuan yang beragam pula. Namun berdasarkan hasil temuan penelitian tersebut terlihat ketidakkonsistenan aspek yang mempengaruhi pengungkapan ISR. Beberapa alasan yang menyebabkan hasil penelitian tersebut menjadi beragam, karena adanya perbedaan waktu observasi, objek yang diteliti, intrepetasi peneliti terhadap laporan keuangan maupun teknik analisis data yang digunakan. Oleh sebab itu perlu dilakukan penelitian kembali dengan menggunakan variabel moderasi, waktu observasi dan objek yang berbeda. Sehingga penelitian ini memiliki tujuan untuk menganalisis pengaruh profitabilitas, leverage dan kepemilikan institusional terhadap pengungkapan ISR dengan ukuran perusahaan sebagai variabel moderasi pada perusahaan yang terdaftar di JII periode 20142019.

\section{TELAAH LITERATUR}

\section{Teori Legitimasi}

Teori legitimasi menjadi dasar teori tanggung jawab sosial yang memiliki hubungan dengan teori stakeholder (Dowling and Pfeffer 1975). Legitimasi adalah cara mempertahankan keberlangsungan hidup suatu perusahaan, legistimasi dapat diperoleh dengan melakukan tindakan sesuai dengan peraturan dan dapat diterima masyarakat (O'Donovan 2002). Perusahaan harus memastikan aktivitasnya mematuhi hukum dan peraturan sosial yang berlaku. Lewat pengungkapan tanggung jawab sosial perusahaan mengharapkan mendapat legitimasi masyarakat dan berdampak positif bagi perusahaan (Deegan 2002). Perusahaan yang mengalami legitimacy gap akan berakibat adanya protes dari stakeholder berakibat pada keberadaan perusahaan, menganggu keseimbangan operasional dan berakhir pada profitabilitas (Grahovar 2011). Kontrak sosial yang bersifat implisit mampu memperbaiki legitimasi perusahaan dengan masyarakat, menaikkan laba perusahaan masa depan dan cara going concern perusahaan (Lindawati and Puspita 2015).

\section{Pengungkapan Islamic Social Reporting (ISR)}

Dasar hukum ISR adalah prinsip dan ide diambil dari Al-Quran dan Hadits (Djuniar and Ningsih 2019). Pelaporan tanggung jawab sosial perusahaan dalam sistem tradisional lebih menitik beratkan aspek material dan etika. Kerangka ISR bertujuan agar pengambil keputusan termasuk investor muslim lebih percaya pada pelaporan perusahaan bahwa telah sesuai dengan prinsip syariah (Ibrahim and Muthohar 2019). Tema yang diungkapan dalam ISR adalah lima, keuangan dan investasi, tema produk dan jasa, karyawan, masyarakat, lingkungan. Selanjutnya dikembangkan menambahkan satu tata kelola perusahaan (Rizfani and Lubis 
2019). Tujuan utama ISR yaitu: pertama bertanggung jawab kepada Tuhan dan masyarakat. Kedua, memperluas transparansi kegiatan ekonomi dengan menyediakan data relevan. ISR menekankan kesetaraan sosial dalam pelaporan lingkungan, kepentingan masyarakat dan karyawan (Mubarok 2019).

\section{Profitabilitas}

Profitabilitas rasio yang mengilustrasikan kekuatan perusahaan mendapatkan laba dalam kurun waktu tertentu, besarnya profitabilitas mempengaruhi perusahaan dan pengungkapan tanggung jawab sosialnya. Tingginya profitabilitas memiliki lebih banyak dana untuk mengembangkan tanggung jawab sosial (Nugroho and Yulianto 2015). Profitabilitas menjadi bagian faktor dapat mempengaruhi pengungkapan ISR. Ketika status keuangan suatu perusahaan sedang baik, maka perusahaan akan mendapat tekanan dari pihak luar di kemudian hari, dan mengakibatkan pengungkapan ISR lebih luas (Novrizal and Fitri 2016).

\section{Leverage}

Struktur modal perusahaan dapat mempengaruhi biaya pelaporan tanggung jawab sosial. Leverage muncul karena perusahaan menggunakan aset dan sumber dana yang menyebabkan perusahaan mengeluarkan biaya tetap selama operasinya. Tingginya suku bunga utang juga mendesak kreditor lebih aktif mengawasi manajemen (Prasetyoningrum 2019). Tingkat leverage yang tinggi mempunyai insentif memberikan informasi, termasuk memberikan lebih banyak informasi sosial kepada dunia luar. Keterbukaan informasi dapat menghilangkan asimetri informasi dan ketidakpastian tentang prospek perusahaan kedepan serta bertujuan untuk membuat kreditor merasa penuh keyakinan untuk tidak melanggar konvensi (perjanjian) yang ada (Ramadhani, Desmiyawati, and Kurnia 2016). Rasio ini dapat memberitahukan perusaaan resiko dari modal yang diperoleh dari utang, dengan adanya dana ini tentunya akan menambah keuntungan dengan resiko harus membayar bunga utang (Arif and Wawo 2016). Penelitian ini menggunakan debt to equity (DER), mengukur bagaimana kemampuan perusahaan membayar hutang (Anggraini and Wulan 2015).

\section{Kepemilikan Institusional}

Struktur perusahaan merupakan faktor cukup kuat mempengaruhi tingkat kepatuhan pengungkapan. Kepemilikan institusional dapat mengontrol manajemen melewati proses pemantauan yang efektif, sehingga mempengaruhi tingkat pengungkapan yang bersifat wajib. Struktur kepemilikan dapat memberikan pemantauan kinerja perusahaan, seperti kewajiban untuk mengungkapkan informasi kepada pemangku kepentingan. Stakeholders yang membutuhkan banyak informasi menjadi penyebab perusahaan akan mengungkapkan informasi tersebut dengan lebih rinci (Nugraheni and Yuliani 2017). Kepemilikan institusional kepemilikan saham perusahaan oleh pemerintah, intitusi keuangan. Kepemilikan institusional mempengaruhi keputusan investasi dalam tanggung jawab sosial (Sari and Rani 2015). 


\section{Ukuran Perusahaan}

Ukuran perusahaan (Firm Size) disebut skala yang berguna untuk mengevaluasi besar atau kecil ukuran industri. Makin besar perusahaan sumber daya akan meningkat, baik itu bidang keuangan, sumber daya manusia maupun fasilitas. Ukuran perusahaan mencerminkan perusahaan memiliki lebih banyak pemangku kepentingan, banyaknya kepemilikan pemangku kepentingan mendorong perusahaan untuk mengungkapkan $I S R$. Besar kecil perusahaan diukur dengan total asset perusahaan, dari jumlah asset lancar sampai dengan jumlah asset tetap (Mais and Engkur 2019). Ukuran perusahaan dapat mempengaruhi luasnya tanggung jawab sosial, dikarenakan tekanan politik yang besar. Perusahaan melaksanakan tanggung jawab sosial dalam jangka panjang dapat menjauhkan dari biaya yang disebabkan adanya tuntutan masyarakat (Sari and Rani 2015). Ukuran perusahaan diukur dengan total aktiva perusahaan, adalah transaksi dimasa lalu dapat memberikan manfaat ekonomi bagi perusahaan dimasa depan (Arif and Wawo 2016).

\section{Pengembangan Hipotesis}

Mekanisme corporate governance dan profitabilitas yang memadai membuat perusahaan lebih serius dalam memenuhi tanggung jawab sosialnya, dengan didapatnya legitimasi masyarakat perusahaan akan mendapatkan dampak meningkatkan keuntungan perusahaan di masa depan (Putri and Christiawan 2014). Penelitian mengenai profitabilitas terhadap pengungkapan ISR sudah pernah dilakukan oleh Taufik, Widianti, and Rafiqoh (2015); Anggraini and Wulan (2015); Hasanah, Widiyanti, and Sudarno (2018); Hussain et al. (2020) menemukan bahwa profitabilitas berpengaruh terhadap pengungkapan ISR, maka dapat dibentuk hipotesis sebagai berikut:

$\mathrm{H}_{1}$ : profitabilitas berpengaruh positif terhadap pengungkapan ISR.

Teori legitimasi yang berkaitan dengan teori stakeholder menjelaskan hubungan tanggung jawab sosial dengan leverage. Mengungkapan ISR mendatangkan keuntungan dapat dijadikan jaminan kreditor dan investor. Dimana pengungkapan tanggung jawab sosial ini sebagai going concern (Putri and Christiawan 2014). Penelitian mengenai leverage terhadap pengungkapan ISR sudah pernah dikaji oleh Anggraini and Wulan (2015); Ramadhani, Desmiyawati, and Kurnia (2016); Pratama, Muchlis, and Wahyuni (2018) menemukan bahwa leverage memiliki pengaruh terhadap pengungkapan ISR, maka dapat dibentuk hipotesis sebagai berikut:

$\mathrm{H}_{2}$ : leverage berpengaruh positif terhadap pengungkapan ISR.

Teori legitimasi dengan adanya sistem corporate governance, maka perusahaan dapat melaksanakan tanggung jawab sosial yang berdampak positif bagi perusahaan seperti meningkatnya keutungan dan terciptanya tata kelola yang harmonis. Pelaporan tanggung jawab sosial juga merupakan kewajiban perusahaan terhadap stakeholder (Putri and Christiawan 2014). Penelitian mengenai kepemilikan institusional terhadap pengungkapan ISR sudah dikaji oleh Nigrum, Fachrurrozie, and Jayanto (2013); Pratama, Muchlis, and Wahyuni (2018); Widyanti and Cilarisinta (2020) menemukan bahwa kepemilikan institusional memiliki pengaruh terhadap pengungkapan $I S R$, maka dapat dibentuk hipotesis sebagai berikut:

$\mathrm{H}_{3}$ : kepemilikan institusional berpengaruh positif terhadap pengungkapan ISR. 
Ukuran perusahaan disebut skala pententu ukuran dari perusahaan. Makin Perusahaan besar semakin banyak informasi tersedia, sehingga memudahkan investor dalam mengambil keputusan investasi (Hartini 2018). Penelitian yang dilakukan Sabrina and Betri (2018) menyatakan bahwa ukuran perusahaan memoderasi pengaruh profitabilitas terhadap pengungkapan ISR, maka dapat dibentuk hipotesis sebagai berikut:

$\mathrm{H}_{4}$ : ukuran perusahaan memoderasi pengaruh profitabilitas terhadap pengungkapan $I S R$.

Ukuran perusahaan dapat mengambarkan jumlah leverage perusahaan. Perusahaan besar memiliki manjemen yang efektif dalam memaksimalkan profit, untuk perusahaan yang dikelola dengan buruk akan memiliki profit rendah, untuk mengimbangi kekuragan dana perusahaan memiliki beberapa opsi salah satunya adalah leverage (Sabrina and Betri 2018). Penelitian Sabrina and Betri (2018); Yusuf and Shayida (2020) menyatakan bahwa ukuran perusahaan memoderasi hubungan leverage terhadap pengungkapan ISR, sehingga dapat dibentuk hipotesis sebagai berikut:

$\mathrm{H}_{5}$ : ukuran perusahaan memoderasi pengaruh leverage terhadap pengungakapan ISR.

Kepemilikan institusional unsur yang dapat memengaruhi kinerja perusahaan. Kepemilikan institusional dapat mengoptimalkan pemantuan kinerja manajemen agar optimal. Kepemilikan institusional dapat melangsungkan pengawasan bergantung jumlah investasi yang dilakukan (Firdaus, Darlis, and Indrawati 2017). Perusahaan yang besar cenderung lebih mudah menarik publik. Perusahaan besar tentu akan lebih banyak melakukan pengungkapan, karena besarnya tekanan yang didapat dan menjaga citra dan reputasi perusahaan tersebut. Banyaknya jumlah pengungkapan akan membuat keputusan investasi yang baik dan menarik para investor (Sabrina and Betri 2018), sehingga dapat dibentuk hipotesis sebagai berikut:

$\mathrm{H}_{6}$ : ukuran perusahaan memoderasi pengaruh kepemilikan institusional terhadap pengungkapan ISR.

\section{METODE PENELITIAN}

Penelitian ini merupakan penelitian kuantitatif dengan menggunakan data sekunder berupa data panel. Pengumpulan data dilakukan dengan studi kepustakaan dan studi dokumentasi. Populasi seluruh perusahaan terdaftar pada Jakarta Islamic Index (JII) periode 2014-2019 diambil melalui website resmi www.idx.co.id. Teknik sampel menggunakan metode purposive sampling, dengan kriteria: (1) Perusahaan terdaftar pada JII rentang waktu 2014-2019. (2) Menerbitkan laporan tahunan periode 2014-2019. (3) Menerbitkan laporan tanggung jawab sosial pada laporan tahunan. (4) Memiliki data variabel yang digunakan. Sehingga terpilih sampel perusahaan dengan kode ADRO, AKRA, ASII, BSDE, ICBP, INCO, INDF, KLBF, PGAS, PTPP, TLKM, UNTR, UNVR, WIKA. Model penelitian ini mempergunakan moderated regression analysis (MRA). MRA merupakan pendekatan analitik dalam mempertahankan intregitas sampel dan memberikan dasar yang berguna mengontrol pengaruh variabel moderasi (Ghozali 2016). Berikut persamaan regresi untuk MRA:

$\mathrm{Y}=\alpha+\beta_{1} \mathrm{X} 1+\beta_{2} \mathrm{X} 2+\beta_{3} \mathrm{X} 3+\varepsilon$ 
$\mathrm{Y}=\alpha+\beta_{1} \mathrm{X} 1+\beta_{2} \mathrm{X} 2+\beta_{3} \mathrm{X} 3+\beta_{4}(\mathrm{X} 1 * \mathrm{Z})+\beta_{5}(\mathrm{X} 2 * \mathrm{Z})+\beta_{6}(\mathrm{X} 3 * \mathrm{Z})+\varepsilon$

Dimana:

Y = Pengungkapan Islamic Social Reporting (ISR)

$\alpha \quad=$ Konstanta

$\beta \quad=$ Koefisien Regresi

$\mathrm{X} 1=$ Profitabilitas $(R O A)$

$\mathrm{X} 2=$ Leverage $(D E R)$

$\mathrm{X} 3=$ Kepemilikan Institusional (KI)

$\mathrm{Z}=$ Ukuran Perusahaan (SIZE)

$\varepsilon \quad=$ Error

\section{HASIL DAN PEMBAHASAN PENELITIAN}

\section{Statistik Deskriptif}

Tabel 1. Statistik Deskriptif

\begin{tabular}{lccccc}
\hline & N & Minimum & Maximum & Mean & Std. Deviation \\
\hline ROA & 84 & 0,0283 & 0,6831 & 0,287549 & 0,1237482 \\
DER & 84 & 0,3804 & 2,2612 & 0,970894 & 0,3573286 \\
KI & 84 & 0,4138 & 0,9998 & 0,865897 & 0,1713009 \\
ISR & 84 & 0,4662 & 0,8469 & 0,788684 & 0,0493491 \\
SIZE & 84 & 1,7022 & 5,6910 & 5,423928 & 0,4461788 \\
\hline Valid N (listwise) & 84 & & & & \\
\hline
\end{tabular}

Sumber: data sekunder (diolah)

Berdasarkan Tabel 1 memperlihatkan bahwa $R O A$ memiliki nilai terendah 0,0283 , nilai tertinggi 0,6831 , nilai rata-rata 0,287549 , dan standar deviasi 0,1237482. DER memiliki nilai terendah 0,3804, nilai tertinggi 2,2612, nilai ratarata 0,970894, dan standar deviasi 0,3573286. Kepemilikan institusional (KI) memiliki nilai terendah 0,4138 , nilai tertinggi 0,9998 , rata-rata 0,865897 , standar deviasi 0,1713009 . ISR nilai terendah 0,4662 , nilai tertinggi 0,8469 , rata-rata 0,788684, dan standar deviasi 0,0493491. Ukuran perusahaan (SIZE) nilai terendah 1,7022 , nilai tertinggi 5,6910, rata-rata 5,42392, dan standar deviasi 0,4461788 .

\section{Hasil Normalitas}

Tabel 2. Hasil Normalitas

\begin{tabular}{llc}
\hline & & Unstandardized Residual \\
\hline $\boldsymbol{N}$ & & 84 \\
Normal & Mean & 0,0000000 \\
Parameters ${ }^{\boldsymbol{b}} \boldsymbol{\text { Std. Deviation }}$ & Absolute & 0,03344535 \\
Most Extreme & Positive & 0,065 \\
Differences & Negative & 0,050 \\
& & $-0,065$ \\
Test Statistic & & 0,065 \\
Asymp. Sig. (2-tailed) & 0,200 \\
\hline
\end{tabular}

Sumber: data sekunder (diolah) 
Uji normalitas menggunakan one-sample kolmogorov-smirnov test. Tabel 2 menunjukkan nilai signifikansi (Asymp. Sig.) sebesar 0,200, berarti nilai signifikansi lebih besar dari 0,05. Sehingga dapat dikatakan bahwa data residual berdistribusi normal.

\section{Hasil Multikolonieritas}

Tabel 3. Hasil Multikolonieritas

\begin{tabular}{|c|c|c|}
\hline \multirow{2}{*}{ Model } & \multicolumn{2}{|c|}{ Collinearity Statistics } \\
\hline & Tolerance & VIF \\
\hline$R O A$ & 0,749 & 1,335 \\
\hline DER & 0,692 & 1,446 \\
\hline $\mathrm{KI}$ & 0,586 & 1,707 \\
\hline SIZE & 0,938 & 1,066 \\
\hline
\end{tabular}

Hasil uji multikolinearitas dapat dilihat pada Tabel 3, dimana syarat uji multikolinearitas adalah nilai $V I F<10$ atau nilai tolerance $>0,10$. Dari seluruh variabel bebas diperoleh nilai toleransi lebih besar dari 0,01 dan nilai VIF lebih kecil 10. Maka dapat dikatakan bahwa tidak terdapat multikolonieritas pada variabel $R O A, D E R$, kepemilikan institusional, dan ukuran perusahaan terhadap model regresi.

\section{Hasil Heteroskdastisitas}

Tabel 4. Hasil Heteroskedastisitas

\begin{tabular}{lccc}
\hline \multicolumn{1}{c}{ Model } & $\begin{array}{c}\text { Unstandardized } \\
\text { Coefficients }\end{array}$ & $\boldsymbol{T}$ & Sig. \\
\hline (Constant) & 0,090 & 3,186 & 0,002 \\
ROA & $-0,014$ & $-0,711$ & 0,479 \\
DER & $-0,008$ & $-1,121$ & 0,266 \\
KI & $-0,012$ & $-0,706$ & 0,482 \\
SIZE & $-0,008$ & $-1,523$ & 0,132 \\
\hline Sumber: data sekunder (diolah) & &
\end{tabular}

Berdasarkan Tabel 4, diketahui bahwa nilai signifikan dari seluruh variabel bebas lebih besar dari 0,05. Sehingga dapat dikatakan bahwa tidak ada gejala heterokedastisitas.

\section{Hasil Autokolerasi}

Tabel 5. Hasil Autokolerasi

\begin{tabular}{ccccc}
\hline $\boldsymbol{R}$ & $\begin{array}{c}\boldsymbol{R} \\
\text { Square }\end{array}$ & $\begin{array}{c}\text { Adjusted } \boldsymbol{R} \\
\text { Square }\end{array}$ & $\begin{array}{c}\text { Std. Error of } \\
\text { the Estimate }\end{array}$ & $\begin{array}{c}\text { Durbin- } \\
\text { Watson }\end{array}$ \\
\hline $0,735^{\text {a }}$ & 0,541 & 0,517 & 0,03428 & 1,811 \\
\hline \multicolumn{4}{l}{ Sumber: data sekunder (diolah) }
\end{tabular}


Berdasarkan Tabel 5 Nilai Durbin-Watson berada diposisi du $<\mathrm{d}<4-\mathrm{du}$, yaitu $1,7462<1,811<2,2538$. Hal tersebut berarti tidak terjadi autokolerasi positif maupun autokolerasi negatif.

Hasil Moderated Regression Analysis (MRA)

Tabel 6 Hasil Moderated Regression Analysis (MRA)

\begin{tabular}{|c|c|c|c|c|}
\hline \multirow{2}{*}{ Model } & \multicolumn{2}{|c|}{$\begin{array}{c}\text { Unstandardized } \\
\text { Coefficients }\end{array}$} & \multirow{2}{*}{$T$} & \multirow{2}{*}{ Sig. } \\
\hline & $\boldsymbol{B}$ & $\begin{array}{c}\text { Std. } \\
\text { Error }\end{array}$ & & \\
\hline (Constant) & 1,770 & 0,714 & 2,478 & 0,015 \\
\hline$R O A$ & 1,948 & 1,475 & 1,321 & 0,191 \\
\hline$D E R$ & $-1,806$ & 0,669 & $-2,699$ & 0,009 \\
\hline KI & 0,013 & 0,483 & 0,026 & 0,979 \\
\hline ROA_SIZE & $-0,327$ & 0,269 & $-1,218$ & 0,227 \\
\hline$D E R \_S I Z E$ & 0,324 & 0,121 & 2,666 & 0,009 \\
\hline KI_SIZE & $-0,007$ & 0,089 & $-0,081$ & 0,936 \\
\hline \multicolumn{4}{|l|}{$F$} & 19,762 \\
\hline \multicolumn{4}{|l|}{ Sig. } & 0,000 \\
\hline \multicolumn{4}{|l|}{$R$} & 0,803 \\
\hline \multicolumn{4}{|l|}{$R$ Square } & 0,645 \\
\hline \multicolumn{4}{|c|}{ Adjusted $R$ Square } & 0,613 \\
\hline
\end{tabular}

Berdasarkan Tabel 6 dapat dilihat dilihat bahwa nilai signifikansi $R O A$ sebesar 0,191, berarti lebih besar dari 0,05. Maka dapat dinyatakan bahwa $R O A$ secara individual tidak berpengaruh terhadap pengungkapan $I S R\left(\mathrm{H}_{1}\right.$ ditolak). Nilai signifikansi $D E R$ sebesar 0,009, berarti lebih kecil dari 0,05 dan koefisien bernilai negatif. Maka dapat dinyatakan bahwa $D E R$ secara individual berpengaruh negatif terhadap pengungkapan ISR $\left(\mathrm{H}_{2}\right.$ ditolak). Nilai signifikansi KI sebesar 0,979, berarti lebih besar dari 0,05. Maka dapat dinyatakan bahwa kepemilikan institusional secara individual tidak berpengaruh terhadap pengungkapan $I S R\left(\mathrm{H}_{3}\right.$ ditolak).

Kemudian nilai signifikansi ROA_SIZE sebesar 0,227, berarti lebih besar dari 0,05. Maka dapat dinyatakan bahwa ukuran perusahaan tidak dapat memoderasi pengaruh $R O A$ terhadap pengungkapan $I S R\left(\mathrm{H}_{4}\right.$ ditolak). Nilai signifikansi DER_SIZE sebesar 0,009, berarti lebih kecil dari 0,05. Maka dapat dinyatakan bahwa ukuran perusahaan dapat memoderasi pengaruh $D E R$ terhadap pengungkapan ISR ( $\mathrm{H}_{5}$ diterima). Nilai signifikansi KI_SIZE sebesar 0,936, berarti lebih besar dari 0,05. Maka dapat dinyatakan bahwa ukuran perusahaan tidak dapat memoderasi pengaruh kepemilikan institusional terhadap pengungkapan $I S R$ ( $\mathrm{H}_{6}$ ditolak).

Selanjutnya nilai signifikan pada pengujian simultan sebesar 0,000 , berarti kecil dari 0,05 dan nilai Adjusted $R$ Square sebesar 0,613. Maka dapat dinyatakan bahwa variabel bebas (ROA, DER, KI) dan variabel moderasi (ROA_SIZE, $D E R \_S I Z E$, KI_SIZE) secara bersama-sama mempengaruhi pengungkapan ISR dengan besar pengaruh yaitu 0,613 (61,3\%). 


\section{Pengaruh Profitabilitas Terhadap Pengungkapan ISR}

Hasil hipotesis $\mathrm{H}_{1}$ ditolak, artinya bahwa $R O A$ tidak berpengaruh terhadap pengungkapan ISR. Perusahaan mempunyai profitabilitas tinggi akan lebih berorientasi laba semata, sehingga dana yang digunakan untuk pemanfaatan kegiatan sosial kurang maksimal. Terdapatnya profitabilitas tinggi tidak menjamin melakukan aktivitas sosial yang luas karena laba akan lebih diutamakan untuk kegiatan operasi. Penelitian ini tidak mendukung teori legistimasi. Legistimasi yang tinggi akan memiliki peluang melakukan pengungkapan ISR lebih luas untuk menggambarkan kinerja perusahan agar dapat diterima masyarakat. Hasil penelitian ini searah dengan penelitian Rosiana, Arifin, and Hamdani (2015); Nofitasari and Endraswati (2019) yang menyatakan bahwa ROA tidak berpengaruh terhadap pengungkapan ISR. Namun hasil penelitian ini bertolak belakang dengan penelitian Taufik, Widianti, and Rafiqoh (2015); Anggraini and Wulan (2015); Hasanah, Widiyanti, and Sudarno (2018); Hussain et al. (2020) yang menyatakan bahwa profitabilitas berpengaruh terhadap pengungkapan ISR.

\section{Pengaruh Leverage Terhadap Pengungkapan ISR}

Hasil hipotesis $\mathrm{H}_{2}$ ditolak, artinya bahwa $D E R$ tidak berpengaruh terhadap pengungkapan ISR. Tinggi rendahnya tingkat leverage tidak berpengaruh terhadap perluasan ISR, karena menyediakan informasi adalah kewajiban perusahaan terhadap steakholder. Pelaporan tanggung jawab sosial merupakan tindakan wajib mesti dilaksanakan perusahaan menurut Undang-Undang Nomer 40 Tahun 2007 tentang peseroan terbatas (PT). Maka besar kecilnya leverage perusahaan tidak merubah kewajiban untuk mengungkapan tanggung jawab sosial. Hasil penelitian ini tidak mendukung teori legistimasi bahwa tinggi leverage akan membuat perusahaan melakukan pengungkapan $I S R$ lebih kompleks untuk membentuk citra baik perusahaan. Sejalan dengan penelitian Hasanah, Widiyanti, and Sudarno (2018); Astuti and Nurkhin (2019) yang menyatakan bahwa DER tidak berpengaruh terhadap pengungkapan ISR. Hasil penelitian ini bertolak belakang dengan penelitian Anggraini and Wulan (2015); Ramadhani, Desmiyawati, and Kurnia (2016); Pratama, Muchlis, and Wahyuni (2018) yang menyatakan bahwa leverage memiliki pengaruh terhadap pengungkapan ISR.

\section{Pengaruh Kepemilikan Institusional Terhadap Pengungkapan ISR}

Hasil hipotesis $\mathrm{H}_{3}$ ditolak, artinya bahwa kepemilikan institusional tidak berpengaruh terhadap pengungkapan ISR. Kepemilikan institusional juga dianggap kurang efektif dalam mekanisme monitoring dalam pengambilan keputusan. Kepemilikan institusional diduga tidak peduli dengan tanggung jawab untuk stakeholder yang lain dan hanya memaksimalkan keuntungan pribadi. Hasil penelitian ini tidak sejalan teori legistimasi karena kepemilikan instusional lebih berfokus pada kepentingan mereka tanpa peduli stakeholder lain. Hasil penelitian ini sejalan dengan Nugraheni and Yuliani (2017); Firdaus, Darlis, and Indrawati (2017) yang menyatakan bahwa kepemilikan intitusional tidak berpengaruh terhadap pengungkapan ISR. Hasil penelitian ini bertolak belakang dengan Nigrum, Fachrurrozie, and Jayanto (2013); Pratama, Muchlis, and Wahyuni (2018); Widyanti and Cilarisinta (2020) yang menyatakan bahwa kepemilikan institusional memiliki pengaruh terhadap pengungkapan ISR. 


\section{Ukuran Perusahaan Memoderasi Pengaruh Profitabilitas Terhadap Pengungkapan ISR}

Hasil hipotesis $\mathrm{H}_{4}$ ditolak, artinya bahwa ukuran perusaahaan tidak mampu memoderasi pengaruh ROA terhadap pengungkapan ISR. Perusahaan dengan skala yang besar tidak selalu berada dalam kondisi keuangan yang baik. Karena kondisi keuangan yang baik menjadi salah satu faktor perusahaan dapat luas melakukan pengungkapan ISR. Tidak sejalan dengan teori legistimasi karena perusahaan dengan skala besar perlunya kehati-hatian dalam melakukan atau kebijakan, tindakan dengan dampak positif agar diterima lingkungan sekitar perusahaan. Dampak negatif dari perusahaan yang nantinya akan berakibat pada hilangnya dukungan dari para stakeholder, menurunya kinerja dan profitabilitas yang diperoleh akan menurun. Saat profitabilitas perusahaan rendah tidak akan memiliki cukup melakukan ISR lebih luas. Hasil penelitian ini mendukung penelitian Yusuf and Shayida (2020) yang menyatakan bahwa ukuran perusahaan tidak bisa memoderasi pengaruh profitabilitas terhadap pengungkapan ISR. Hasil penelitian ini bertolak belakang dengan penelitian Sabrina and Betri (2018) menyatakan bahwa ukuran perusahaan memoderasi pengaruh profitabilitas terhadap pengungkapan ISR.

\section{Ukuran Perusahaan Memoderasi Pengaruh Leverage Terhadap Pengungkapan ISR}

Hasil hipotesis $\mathrm{H}_{5}$ diterima, artinya bahwa ukuran perusahaan dapat memoderasi pengaruh $D E R$ terhadap pengungkapan ISR. Perusahaan yang besar tentunya memiliki banyak stakeholder dan memiliki tuntutan informasi perusahaan. Penelitian ini sejalan dengan teori legistimasi bahwa perusahaan dengan skala besar sumber daya yang melimpah dapat digunakan melakukan segala aktivitas perusahaan secara maksimal, yang berdampak positif bagi perusahaan salah satunya kepecayaan dari para kreditur. Perusahaan dengan hutang besar akan membuat perusahaan memiliki tekanan yang besar dari stakeholder, dampak dari tekanan perusahaan ini membuat perusahaan memberikan informasi yang lebih luas, melakukan pengungkapan ISR lebih luas adalah cara untuk melonggarkan tekanan dari para kreditur agar kerditur percaya perusahaan tidak melanggar perjanjian. Hasil penelitian ini sejalan dengan penelitian Sabrina and Betri (2018); Yusuf and Shayida (2020) yang menyatakan bahwa ukuran perusahaan dapat memoderasi hubungan leverage terhadap pengungkapan ISR kearah positif.

\section{Ukuran Perusahaan Memoderasi Pengaruh Kepemilikan Institusional Terhadap Pengungkapan ISR}

Hasil hipotesis $\mathrm{H}_{6}$ ditolak, artinya bahwa ukuran perusahaan tidak mampu memoderasi pengaruh kepemilikan institusional terhadap pengungkapan ISR. perusahaan dengan jumlah kepemilikan institusional yang besar tidak menjamin dapat melakukan pengungkan ISR yang lebih luas. Penelitian ini tidak mendukung teori legistimasi, hubungan baik perusahaan dengan steakholder tidak membuat kepemilikan institusional merasa memiliki tanggung jawab dan ikut serta melakukan pengawasan terhadap kepatuhan pelaporan yang dilakukan perseroan. Perusahaan yang besar lebih condong jumlah saham kepemilikan intitusional besar. Besarnya jumlah saham yang dimiliki kepemilikan institusional tidak 
berdampak pengawasan yang dilakukan. Kepemilikan institusi dalam perusahaan lebih cenderung melakukan pengendalian untuk kepentingan sendiri dalam memaksimalkan keuntungan bukan kapentingan stakeholder.

Dari hasil penelitian yang telah dilakukan bahwa faktor-faktor yang mempengaruhi pengungkapan ISR tidak berpengaruh. Setelah melakukan pengujian dengan menambahkan variabel ukuran perusahaan sebagai variabel moderasi, ukuran perusahaan mampu memoderasi pengaruh leverage terhadap pengungkapan ISR. Perusahaan besar yang memiliki peluang meningkatkan sumber daya yang dimiliki melalui dana yang dipercaya kreditur kepada perusahaan yang nantinya akan dapat memberikan dampak positif. Maka perusahaan dalam upaya memperluas pengungkapan ISR dapat dilakukan dengan memberikan kesan atau citra baik kepada para kreditur, karena dana yang diberikan oleh kreditur dapat digunakan untuk memperluas sumber daya yang nantininya juga berdampak pada pengungkapan ISR.

\section{KESIMPULAN}

Profitabilitas, Laverage dan Kepemilikan Institusional ternyata tidak berpengaruh terhadap pengungkapan ISR. Sedangkan ukuran perusahaan dapat memoderasi pengaruh leverage terhadap pengungkapan ISR. Namun ukuran perusahaan tidak dapat memoderasi pengaruh profitabilitas dan kepemilikan institusional terhadap pengungkapan ISR.

Rasio yang digunakan dalam penelitian hanya sebatas profitabilitas dan leverage karena masih ada raiso yang dapat digunakan. Objek yang dilakukan hanya pada Jakarta Islamic Index sehingga tidak dapat dijadikan acuan untuk objek lain.

Penelitian selanjutnya diharapkan dapat menambahkan jumlah sampel pada perusahaan lain seperti ISSI. Dapat menambahkan variabel lain yang dapat mempengaruhi pengungkapan ISR. Masa penelitian yang ditambahkan agar dapat mengetahui perkembangan pengungkapan $I S R$ dari tahun ke tahun.

\section{DAFTAR PUSTAKA}

Affandi, Hendri, and Meta Nursita. 2019. "Profitabilitas, Likuiditas, Leverage, Dan Ukuran Perusahaan: Sebuah Analisis Islamic Social Reporting (ISR) Pada Perusahaan Yang Terdaftar Di JII.” Majalah Ilmiah Bijak 16 (1): 111. https://doi.org/10.31334/bijak.v16i1.318.

Anggraini, Anita, and Mulyaning Wulan. 2015. "Faktor Financial -Non Financial

Dan Tingkat Pengungkapan Islamic Social Reporting (ISR)." JAKIS: Jurnal Akuntansi Dan Keuangan Islam 3 (2): 161-84. https://doi.org/10.35836/jakis.v3i2.35.

Arif, Fitri Aulia, and Andi Wawo. 2016. "Pengaruh Ukuran Perusahaan, Leverage, Dan Likuiditas Terhadap Pengungkapan Corporate Social Responsibility Dengan Profitabilitas Sebagai Variabel Moderasi." ASSETS: Jurnal Ekonomi, Manajemen \& Akuntansi 6 (2): 177-95. http://journal.uin-alauddin.ac.id/index.php/assets/article/view/2883.

Astuti, Wiji, and Ahmad Nurkhin. 2019. "The Role of Islamic Governance on 
Islamic Social Reporting Disclosure of Indonesia Islamic Banks Pendahuluan." Conference on Islamic Management Accounting and Economics 2: 26-36. https://journal.uii.ac.id/CIMAE/article/view/12751.

Deegan, Craig. 2002. "Introduction: The Legitimising Effect of Social and Environmental Disclosures - a Theoretical Foundation." Accounting, Auditing \& Accountability Journal $15 \quad$ (3): 282-311. https://doi.org/10.1108/09513570210435852.

Djuniar, Lis, and Ita Ningsih. 2019. "Pengaruh Return On Asset Dan Program Penilaian Peringkat Terhadap Pengungkapan Islamic Social Reporting Dengan Ukuran Perusahaan Sebagai Variabel Intervening (Studi Kasus Pada Perusahaan Yang Terdaftar Di Indeks Saham Syariah Indonesia).” Jurnal Media Wahana Ekonomika 16 (1): 30-39. https://doi.org/10.31851/jmwe.v16i1.3406.

Dowling, John, and Jeffrey Pfeffer. 1975. "Organizational Legitimacy: Social Values and Organizational Behavior.” The Pacific Sociological Review 18 (1): 122-36. https://doi.org/10.2307/1388226.

Firdaus, Indra, Edfan Darlis, and Novita Indrawati. 2017. "Pengaruh Kinerja Keuangan, Kepemilikan Institusional, Ukuran Dewan Pengawas Syariah, Leverage Terhadap Pengungkapan Islamic Social Reporting Pada Perbankan Syariah Di Indonesia (Studi Pada Perbankan Syariah Tahun 2013-2015)." Jurnal Online Mahasiswa Fakultas Ekonomi 4 (1): 30953109. https://jom.unri.ac.id/index.php/JOMFEKON/article/view/18980.

Ghozali, Imam. 2016. Aplikasi Analisis Multivariete Dengan Program IMB SPSS 23. Edited by Prayoga Harto. 8th ed. Semarang: Badan Penerbit Universitas Diponegoro.

Grahovar, Marina. 2011. "The Use of Corporate Responsibility Reports- For Managing Legitimacy." In 1st CSEAR Paris, France, 1-22. http://hdl.handle.net/2077/30504.

Hartini, Titin. 2018. “Analisis Pengaruh Firm Size Dan Profitabiliras Terhadap Islamic Social Reporting (ISR) Dengan Earning Growth Sebagai Variabel Moderating Pada Jakrta Islamic Index (JII)." Nurani: Jurnal Kajian Syariah Dan Masyarakat 18 (1): 137-50. https://doi.org/10.19109/nurani.v18i1.1888.

Hasanah, Nindya Tyas, Novi Wulandari Widiyanti, and S. Sudarno. 2018. "Analisis Pengaruh GCG Dan Kinerja Keuangan Terhadap Pengungkapan Islamic Social Reporting (ISR)." E-Journal Ekonomi Bisnis Dan Akuntansi 5 (2): 115-20. https://doi.org/10.19184/ejeba.v5i2.8645.

Hussain, Arif, Muhammad Khan, Alam Rehman, Shehnaz Sahib Zada, Shumaila Malik, Asiya Khattak, and Hassan Khan. 2020. "Determinants of Islamic Social Reporting in Islamic Banks of Pakistan.” International Journal of Law and Management 63 (1): 1-15. https://doi.org/10.1108/IJLMA-022020-0060.

Ibrahim, Robbi Hasana, and Ahmad Mifdlol Muthohar. 2019. "Pengaruh Komisaris Independen Dan Indeks Islamic Social Reporting Terhadap Nilai Perusahaan Dengan Profitabilitas Sebagai Variabel Intervening." Jurnal Ilmiah Ekonomi Islam 5 (01): 9-20. https://doi.org/10.29040/jiei.v5i01.378.

Lindawati, Ang Swat Lin, and Marsella Eka Puspita. 2015. "Corporate Social 
Responsibility: Implikasi Stakeholder Dan Legitimacy Gap Dalam Peningkatan Kinerja Perusahaan.” Jurnal Akuntansi Multiparadigma 6 (1): 157-74. https://doi.org/10.18202/jamal.2015.04.6013.

Mais, Rimi Gusliana, and Engkur Engkur. 2019. "Influence of Industrial Type, Return on Asset, Company Size, and Institutional Ownership of Islamic Social Reporting Disclosure." In Proceedings of the 5th Annual International Conference on Accounting Research (AICAR 2018) - Series: Advances in Economics, Business and Management Research, 73:173-77. Atlantis Press. https://doi.org/10.2991/aicar-18.2019.37.

Mubarok, Muhammad Sultan. 2019. "The Determinants Of Islamic Social Reporting Disclosure And Its Impact On The Profitability Of Sharia Banks." Journal of Islamic Economics Management and Business 1 (1): 137-72.

https://journal.walisongo.ac.id/index.php/JIEMB/article/view/3742.

Nigrum, Ratna Aditya, Fachrurrozie, and Prabowo Yudo Jayanto. 2013. "Pengaruh Kinerja Keuangan, Kepemilikan Institusional Dan Ukuran Dewan Pengawas Syariah Terhadap Pengungkapan ISR." Accounting $\begin{array}{lllll}\text { Analysis } & \text { Journal } & 2 & \text { (4): }\end{array}$ https://journal.unnes.ac.id/sju/index.php/aaj/article/view/4169.

Nofitasari, Wiwit Ayu, and Hikmah Endraswati. 2019. "Islamic Social Reporting (ISR) Analysis in Indonesia and Malaysia." Al-Iqtishad: Jurnal Ilmu $\begin{array}{lllll}\text { Ekonomi } & \text { Syariah } & 11 & \text { (2): }\end{array}$ https://doi.org/10.15408/aiq.v11i2.10630.

Novrizal, Muhammad Fajrul, and Meutia Fitri. 2016. "Faktor-Faktor Yang Mempengaruhi Pengungkapan Corporate Social Responbility (CSR) Pada Perusahaan Yang Terdaftar Di Jakarta Islamic Index (JII) Tahun 20122015 Dengan Menggunakan Islamic Social Reporting (ISR) Index Sebagai Tolok Ukur." Jurnal Ilmiah Mahasiswa Ekonomi Akuntansi (JIMEKA) 1 (2): 177-89. http://www.jim.unsyiah.ac.id/EKA/article/view/1066.

Nugraheni, Peni, and Rahma Dwi Yuliani. 2017. "Mekanisme Corporate Governance Dan Pengungkapan Islamic Social Reporting Pada Perbankan Syariah Di Indonesia Dan Malaysia." Jurnal Akuntansi Dan Bisnis 10 (1): 130-55.

https://journal.iainkudus.ac.id/index.php/IQTISHADIA/article/view/2501.

Nugroho, Mirza Nurdin, and Agung Yulianto. 2015. "Pengaruh Profitabilitas Dan Mekanisme Corporate Governance Terhadap Pengungkapan CSR Perusahaan Terdaftar JII 2011-2013.” Accounting Analysis Journal 4 (1): 1-12. https://journal.unnes.ac.id/sju/index.php/aaj/article/view/7829.

O'Donovan, Gary. 2002. "Environmental Disclosures in the Annual Report: Extending the Applicability and Predictive Power of Legitimacy Theory." Accounting, Auditing \& Accountability Journal 15 (3): 344-71. https://doi.org/10.1108/09513570210435870.

Prasetyoningrum, Ari Kristin. 2019. "Pengaruh Ukuran Perusahaan, Profitabilitas, Leverage, Efisiensi Biaya, Dan Umur Perusahaan Terhadap Islamic Social Reporting (ISR) Pada Perbankan Syariah Di Indonesia." MALIA: Journal of Islamic Banking and Finance 2 (2): 147-62. https://doi.org/10.21043/malia.v2i2.4780.

Pratama, Nur Abdi, Saiful Muchlis, and Idra Wahyuni. 2018. "Determinan 
Pengungkapan Islamic Social Reporting (ISR) Pada Perbankan Syariah Dengan Komisaris Independen Sebagai Variabel Moderating." AlMashrafiyah: Jurnal Ekonomi, Keuangan, Dan Perbankan Syariah 1 (2): 103-15. https://doi.org/10.24252/al-mashrafiyah.v1i2.4738.

Putri, Rafikia Anggraini, and Yulius Jogi Christiawan. 2014. "Pengaruh Profitabilitas, Likuiditas, Dan Leverage Terhadap Pengungkapan Corporate Social Responsibility." Business Accounting Review 2 (1): 6170. bisnis/article/view/1364.

Ramadhani, Febry, Desmiyawati Desmiyawati, and Pipin Kurnia. 2016. "Pengaruh Ukuran Perusahaan, Profitabilitas, Leverage, Dan Ukuran Dewan Pengawas Syariah Terhadap Pengungkapan Islamic Social Reporting (Studi Empiris Pada Bank Umum Syariah Di Indonesia Tahun 2010-2014)." Jurnal Online Mahasiswa Fakultas Ekonomi 3 (1): 24872500.

https://jom.unri.ac.id/index.php/JOMFEKON/article/view/11923/11568.

Rizfani, Khaerun Nissa, and Deni Lubis. 2019. "Pengungkapan Islamic Social Reporting Pada Perusahaan Di Jakarta Islamic Index.” Al-Muzara'ah 6 (2): 103-16. https://doi.org/10.29244/jam.6.2.103-116.

Rosiana, Rita, Bustanul Arifin, and Muhamad Hamdani. 2015. "Pengaruh Ukuran Perusahaan, Profitabilitas, Leverage, Dan Islamic Governance Score Terhadap Pengungkapan Islamic Social Reporting (Studi Empiris Pada Bank Umum Syariah Di Indonesia Tahun 2010-2012).” Esensi: Jurnal Bisnis Dan Manajemen 5 (1): 87-104. https://doi.org/10.15408/ess.v5i1.2334.

Sabrina, Nina, and Betri Betri. 2018. "Pengaruh Profitabilitas Dan Leverage Terhadap Pengungkapan Islamic Social Reporting Dengan Ukuran Perusahaan Sebagai Variabel Moderasi.” BALANCE: Jurnal Akuntansi Dan Bisnis 3 (1): 324-33. https://jurnal.umpalembang.ac.id/balance/article/view/1156.

Sari, Widya Novita, and Puspita Rani. 2015. "Pengaruh Kepemilikan Intitusional, Kepemilikan Manjerial, Return On Assets (ROA) Dan Ukuran Perusahaan Terhadap Pengungkapan Corporate Social Responsibility (CSR) Pada Perusahaan Manufaktur Yang Terdaftar Di Bursa Efek Indonesia Periode 2011-2013." Jurnal Akuntansi Dan Keuangan 4 (1): 1-20. https://journal.budiluhur.ac.id/index.php/akeu/article/view/392.

Setiawan, Iwan, Haris Faulid Asnawi, and Hafiez Sofyani. 2016. "Apakah Ukuran, Profitabilitas, Dan Praktik Manajemen Laba Memengaruhi Tingkat Pelaksanaan Dan Pelaporan Islamic Social Reporting Pada Perbankan Syariah Di Indonesia?" Jurnal Dinamika Akuntansi Dan Bisnis 3 (2): 65-76. https://doi.org/10.24815/jdab.v3i2.5387.

Sitorus, Anggi Pratiwi. 2019. "Pengaruh Ukuran Perusahaan, Profitabilitas, Dan Ukuran Dewan Komisaris Terhadap Islamic Social Reporiting Dan Reaksi Pasar Di Jakrta Islamic Index Tahun 2014-2017." KITABAH: Jurnal Akuntansi Dan Keuangan Syariah 3 (No. 1): 90-109. http://jurnal.uinsu.ac.id/index.php/JAKS/article/view/5437.

Taufik, Marlina Widianti, and Rafiqoh. 2015. "Pengaruh Islamic Governance Score, Leverage Dan Profitabilitas Terhadap Islamic Social Reporting 
Index Pada Bank Umum Syariah Di Indonesia." Jurnal Manajemen Dan $\begin{array}{lllll}\text { Bisnis } & \text { Sriwijaya } & 13 & \text { (2): }\end{array}$ https://ejournal.unsri.ac.id/index.php/jmbs/article/view/3348.

Widyanti, Afriana Dwi, and Nadia Cilarisinta. 2020. "Pengaruh Profitabilitas, Kepemilikan Institusional Dan Kinerja Lingkungan Terhadap Islamic Social Reporting." KOMPARTEMEN: Jurnal Ilmiah Akuntansi 18 (2): 99109. https://doi.org/10.30595/kompartemen.v18i2.7700.

Yunni, Aristyarini. 2019. "Analisis Pengaruh Ukuran Perusahaan, Profitabilitas, Kinerja Llingkungan Dan Tipe Industri Terdadap Pengungkapan Islamic Social Reporting (ISR) (Studi Empiris Pada Perusahaan Yang Terdapat Di Daftar Efek Syariah (DES) Periode 2013-2017)." Universitas Muria Kudus. http://eprints.umk.ac.id/12102/.

Yusuf, Muhamad, and Nurul Shayida. 2020. "Pengaruh Profitabilitas Dan Leverage Terhadap Pengungkapan Islamic Social Reporting Dengan Ukuran Perusahaan Sebagai Pemoderasi Papa Perusahaan Di JII." Akrual: Jurnal Akuntansi Dan Keuangan 2 (1): 1-17. https://uia.ejournal.id/Akrual/article/view/1041. 